Article

\title{
A Viperin Mutant Bearing the K358R Substitution Lost its Anti-ZIKA Virus Activity
}

\author{
Bénédicte Vanwalscappel, Gilles Gadea ${ }^{\circledR}$ and Philippe Desprès *(i) \\ Université de La Réunion, INSERM U1187, CNRS UMR 9192, IRD UMR 249, \\ Unité Mixte Processus Infectieux en Milieu Insulaire Tropical, Plateforme Technologique CYROI, \\ 97491 Sainte-Clotilde, La Réunion, France; benedicte.vanwalscappel@univ-reunion.fr (B.V.); \\ gilles.gadea@inserm.fr (G.G.) \\ * Correspondence: philippe.despres@univ-reunion.fr
}

Received: 29 January 2019; Accepted: 26 March 2019; Published: 29 March 2019

\begin{abstract}
Interferon-induced viperin (VP) was identified as playing an important role in the innate immune response against Zika virus (ZIKV). The 361 amino acid long human VP protein comprises of a highly conserved C-terminal region, which has been associated with VP antiviral properties against ZIKV. In the present study, we sought to determine whether the very last C-terminal amino-acid residues of VP might play a role in VP-mediated ZIKV inhibition. To address this issue, a recombinant human viperin $\left(\mathrm{rVP}^{\mathrm{wt}}\right)$ was overexpressed by transfection in human epithelial A549 cells. We confirmed that transient overexpression of $\mathrm{rVP}{ }^{\mathrm{wt}}$ prior to ZIKV infection dramatically reduced viral replication in A549 cells. Deletion of the last 17 C-terminal amino acids of VP resulted in a higher expression level of mutant protein compared to wild-type VP. Mutational analysis revealed that residue substitution at positions 356 to 360 with five alanine led to the same phenotype. The charged residues Asp356, Lys358, and Asp360 were then identified to play a role in the weak level of VPwt protein in A549 cells. Mutant VP bearing the D360A substitution partially rescued ZIKV growth in A549 cells. Remarkably, a single Lys-to-Arg substitution at position 358 was sufficient to abrogate VP antiviral activity against ZIKV. In conclusion, our study showed that Asp356, Lys358, and Asp360 may have an influence on biochemical properties of VP. Our major finding was that Lys358 was a key amino-acid in VP antiviral properties against ZIKV.
\end{abstract}

Keywords: innate immunity; ISG; viperin; arbovirus; Zika virus; A549 cells; mutational analysis; protein expression

\section{Introduction}

The recent emergence of mosquito-borne Zika virus (ZIKV) has been associated with an increase in infection severity in humans, thus drawing attention to Zika illness as a public health concern worldwide [1]. ZIKV is an enveloped, single-stranded positive-sense RNA virus that belongs to the flavivirus genus (Flaviviridae family) [2]. Other flaviviruses of medical concern are dengue virus (DENV), Japanese encephalitis virus (JEV), yellow fever virus (YFV), West Nile virus (WNV) and Tick-borne encephalitis virus (TBEV) [2-4]. ZIKV viral strains are clustered into two major lineages, the African and Asia genotypes [5]. ZIKV replication into the cytosol of the host-cell involves viral RNA translation into a polyprotein precursor that is processed by viral and cellular proteases to produce three structural proteins C, prM, and E and seven non-structural (NS) proteins NS1 to NS5 [6,7].

ZIKV infection of human lung epithelial A549 cells with historical strain MR766 (African lineage) and epidemic strain BR15 (Asian lineage) resulted in the activation of a series of interferon-stimulated genes (ISGs) [8]. Viperin (for Virus inhibitory protein endoplasmic reticulum-associated interferon-inducible) has been identified as a major ISG since its expression 
is induced in response to Type I interferons (IFNs), as well as viral infection $[9,10]$. VP exerts antiviral activity against a large range of viruses. Several reports have shown the important role of VP in antiviral immunity against flaviviruses including ZIKV [11-15]. However, the mechanisms by which VP restricts viral infection differ depending on the pathogen [16-21]. In an effort to better understand the molecular basis of VP antiviral action against flaviviruses, it has been observed that VP colocalizes with viral replication complexes, which regroup the NS proteins such as serine protease-NTPase/helicase NS3 [20,21]. Panayiotou et al. demonstrated that VP could interact with the NS3 proteins from JEV, TBEV, YFV, and ZIKV and that the VP-mediated degradation of NS3 might account for the restriction of ZIKV replication [13]. The VP-mediated ZIKV inhibition could also be attributable to a lower production of viral RNA molecules. Indeed, VP can catalyze the conversion of cytidine triphosphate (CTP) into $3^{\prime}$-deoxy-3' $4^{\prime}$-didehydro-CTP (ddhCTP) that acts as a chain terminator for the RNA-dependent RNA polymerase NS5, thus leading to an arrest in viral RNA replication [22].

VP, also known as RSAD2 (for radical SAM domain-containing 2), is a conserved protein with a predicted molecular mass of $42 \mathrm{kDa}$ [10]. The 361 amino acid long VP protein comprises three distinct domains: A variable amino-terminal domain with an amphipathic $\alpha$-helix and a leucine zipper domain, a conserved central domain containing a radical S-adenosyl methionine (SAM) domain and a highly conserved C-terminal domain $[9,10]$. The role of the radical SAM domain in VP antiviral function remains somewhat elusive.

It has been reported that the deletion of the C-terminus amino-acid residue W361 of human viperin abrogates its antiviral activity against hepatitis $C$ virus belonging to the Flaviviridae family [23]. Furthermore, recent works have demonstrated that VP protein mutants lacking the last C-terminal amino-acid residues are attenuated in their ability to inhibit flavivirus infection $[12,14,20]$. In the present study, we investigated the role of amino-acid residues 356 to 360 in VP antiviral properties against ZIKV in human epithelial A549 cells. We showed that the three amino acids at positions 356, 358, and 360 may play an important role in biochemical and antiviral properties of VP.

\section{Results and Discussion}

\subsection{The Last C-Terminal Residues at Positions 356, 358, and 360 Influence VP Protein Level}

It has been reported that the C-terminal amino-acid residues of VP might play a major role in its antiviral action against flaviviruses $[12,14,20]$. To address the role of the five residues located at positions 356 to 360 in VP-mediated ZIKV inhibition, we used a vector plasmid pcDNA3 which overexpressed $\mathrm{rVP} \mathrm{P}^{\mathrm{wt}}$ tagged with a C-terminal FLAG epitope (Figure 1A). It has recently been reported that viral clone BR15 derived from a Brazilian epidemic ZIKV strain BeH819015 replicated efficiently in human epithelial A549 cells [8]. Here, we show that IFN- $\beta$ stimulates expression of endogenous VP mRNA indicating that A549 epithelial cells have the ability to produce VP (Figure S1). rVPwt anti-ZIKV activity was then validated in human epithelial A549 cells transfected at $18 \mathrm{~h}$ with pcDNA3/rVP and then infected $24 \mathrm{~h}$ with ZIKV strain BR15 (Figure S2). Analysis of viral growth showed that rVPwt transient expression prevents ZIKV infection in agreement with a previous report [14].

We investigated the role of the last $\mathrm{C}$-terminal amino-acid residues in $\mathrm{VP}$ antiviral action against ZIKV. Mutations D356A, L357A, K358R, L359A, and D360A were introduced into the rVP't sequence of $\mathrm{pcDNA} 3 / \mathrm{rVP}$ in order to generate a mutant pcDNA3/rVP-Ala ${ }^{356-360}$ (Figure 1A). Given that VP requires its 17 amino-acid C-terminal residues for its anti-DENV activity [20], we also engineered a mutant plasmid pcDNA3/rVP- $\Delta 17$ as a control (Figure $1 \mathrm{~A}$ ). We first analyzed the expression of the two mutants rVP with wild-type rVP in A549 cells transfected $18 \mathrm{~h}$ with either pcDNA3/rVP- $\Delta 17$, pcDNA3/rVP-Ala ${ }^{356-360}$, or pcDNA3/rVP. Immunoblot assay was performed on cell lysates using anti-FLAG ${ }_{\text {tag }}$ or anti-VP antibody (Figure 1B). The use of an antibody against an $\mathrm{N}$-terminal epitope of VP (anti-VP) or its C-terminal tag gave a comparable pattern of protein expression. We observed that $\mathrm{rVP}-\Delta 17$ mutant migrated faster than $\mathrm{rVP}^{\mathrm{wt}}$ and $\mathrm{rVP}-\mathrm{Ala}^{356-360}$ due to the deletion of the last 
C-terminal amino acids. A smaller form of rVP- $\Delta 17$ was also detected in cell lysates but its origin remains to be understood.

A.

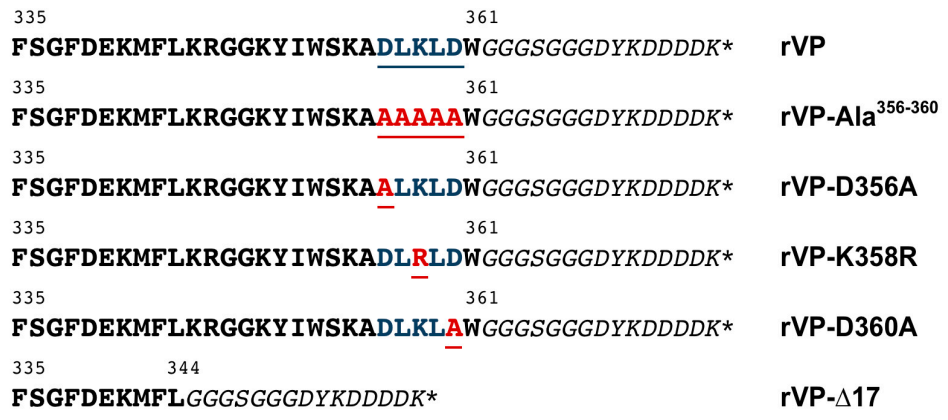

B.

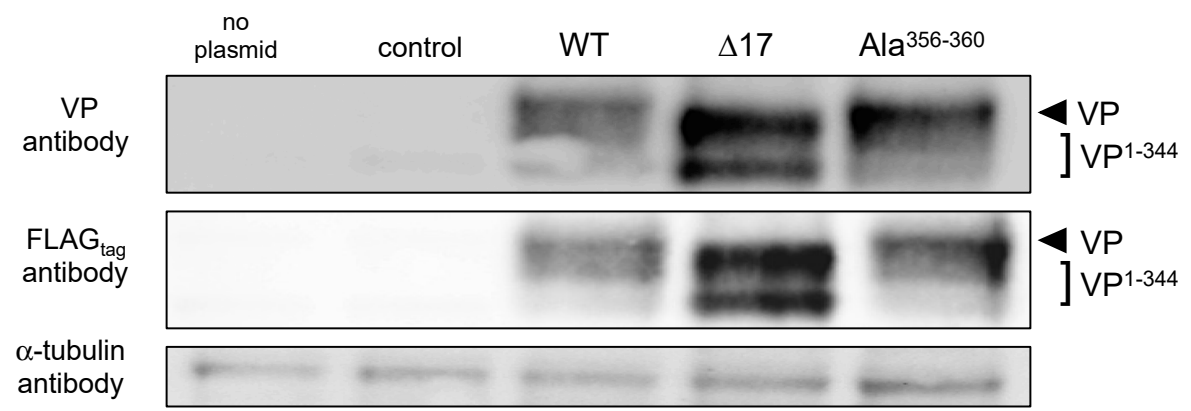

Figure 1. Analysis of rVP mutant expression in A549 cells. In (A), sequence alignment of the C-terminal part (VP-335 to VP-361) of recombinant human viperin ( $\mathrm{rVP}^{\mathrm{wt}}$ ) and its mutants used in this study is shown. The five amino acid residues 356 to 360 mutagenized are highlighted in blue and underlined. The substitutions are highlighted in red and underlined. The glycine-serine spacer and the FLAG tag $_{\text {ta }}$ sequence adjacent to the C-terminus of rVP (W-361) are shown in italics. In (B), the analysis of rVP expression by immunoblot assay is shown. A549 cells were transfected at $18 \mathrm{~h}$ with $\mathrm{pcDNA3} / \mathrm{rVP}$ (WT), pcDNA3/rVP- $\Delta 17\left(\mathrm{VP}^{1-344}\right)$ or pcDNA3/rVP-Ala ${ }^{356-360}\left(\mathrm{Ala}^{356-360}\right)$. As controls, cells were transfected with pcDNA3/RenLUC (control) or mock-transfected (no plasmid). The $\alpha$-tubulin protein served as a protein loading control.

We observed higher protein levels for rVP-Ala ${ }^{356-360}$ and rVP- $\Delta 17$ in A549 cells than for rVPwt (Figure 1B). As residues Asp356, Leu357, Lys358, Leu359, and Asp360 might play a role in VP expression, we decided to generate mutant plasmids pcDNA3/rVP bearing the individual D356A, K358R, or D360A substitution (Figure 1A). The expression of the three mutant rVPs was assessed in A549 cells by immunoblot assay and FACS analysis (Figure 2). Both $\mathrm{PVP}^{\mathrm{wt}}$ and rVP-Ala ${ }^{356-360}$ were used as controls. The immunoblot assay using anti-FLAG tag $_{\text {or }}$ anti-VP antibody, revealed that protein levels of rVP-D356A, rVP-K358R, and rVP-D360A were increased compared to VP ${ }^{\mathrm{wt}}$ (Figure 2A). FACS analysis confirmed the higher protein levels of mutant rVPs (Figure 2B). These results suggest that each of the charged residues Asp356, Lys358, and Asp360 may have an influence on the VP protein level in A549 cells.

We next sought to determine whether the expression of mutant rVPs may have an effect on cell metabolic activity. A549 cells were transfected $18 \mathrm{~h}$ with plasmids expressing rVP't or its mutants and cell metabolic activity was measured $24 \mathrm{~h}$ later by a MTT assay (Figure 3). Expression of the rVP-D356A and rVP-D360A resulted in a weak or moderate reduction in cell metabolic activity whereas rVPwt showed no effect. Interestingly, mutant rVP bearing the K358R substitution was responsible for a severe decrease in cell metabolic activity. Thus, the expression of rVP-K358R has a greater impact on the metabolism of A549 cells. 
A.

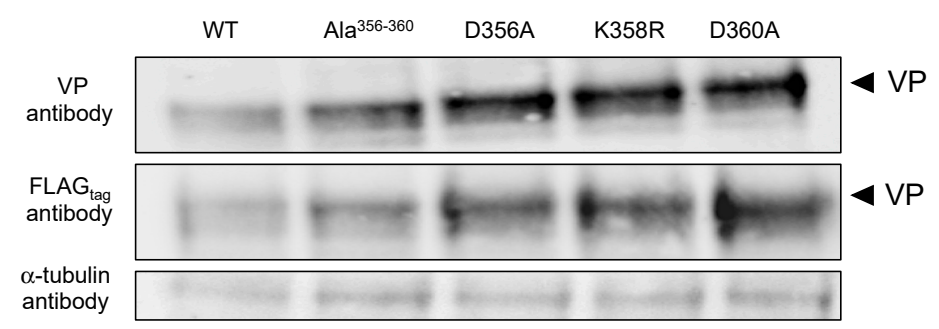

B.

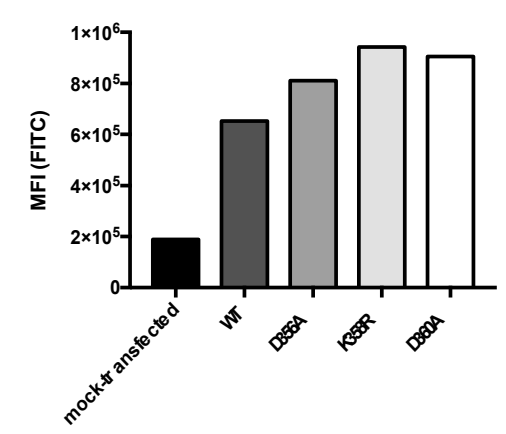

Figure 2. Expression of mutant rVPs bearing the D356A, K358R, and D360A substitutions in A549 cells. A549 cells were transfected at $18 \mathrm{~h}$ with $\mathrm{pcDNA3} / \mathrm{rVP}$ (WT), pcDNA3/rVP-Ala ${ }^{356-360}$ (Ala ${ }^{356-360}$ ), pcDNA3/rVP-D356A (D356A), pcDNA3/rVP-K358R (K358R), or pcDNA3/rVP-D360A (D360A). In (A), an immunoblot assay was performed with anti-FLAG tag $_{\text {on }}$ or anti-VP antibody. The $\alpha$-tubulin protein served as a protein loading control. In (B), FACS analysis using anti-FLAG tag $_{\text {antibody was performed }}$ on mock-transfected (control) or transfected cells and the mean of fluorescence intensity (MFI) of rVP-positive cells is shown.

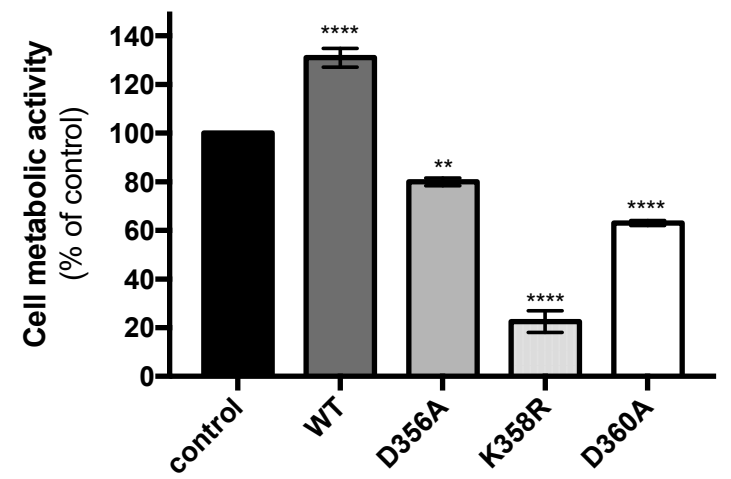

Figure 3. Metabolic activity of cells expressing rVP mutants. A549 cells were transfected at $18 \mathrm{~h}$ with pcDNA3/rVP (WT), pcDNA3/rVP-D356A (D356A), pcDNA3/rVP-K358R (K358R), or pcDNA3/rVP-D360A (D360A) and cell metabolic activity was measured $24 \mathrm{~h}$ later (42 $\mathrm{h}$ post-transfection) using a MTT assay. As a plasmid control, cells were transfected with pcDNA3/RenLUC (control). Viability was expressed as the percentage of cell metabolic activity in assay relative to that in control. Results were expressed as the mean ( \pm SEM) from three independent experiments.

We asked whether the effect of rVP-K358R on cell metabolic activity relates to a change in its intracellular distribution in A549 cells. It has been reported that VP localizes to the cytosolic face of the ER compartment [24]. We visualized the expression of rVPwt and its mutants at positions 356, 358,

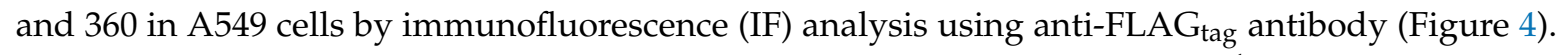
A similar pattern had been observed between rVP-D356A, rVP-D360A and rVPwt. For the rVP-K358R mutant, a pronounced perinuclear fluorescent signal was visualized suggesting that the Lys-to-Arg 
substitution at position 358 might have had an influence on the subcellular distribution of rVP in A549 cells.
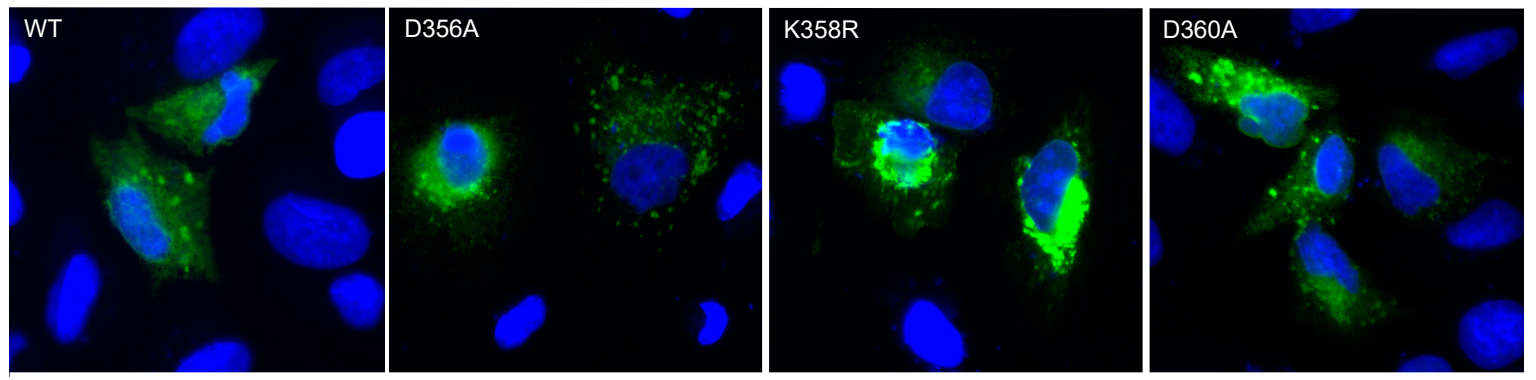

Figure 4. Intracellular expression of VP mutants. A549 cells were transfected at $18 \mathrm{~h}$ with plasmids expressing rVP ${ }^{\mathrm{wt}}$, rVP-D356A, rVP-K358R, or rVP-D360A. Permeabilized cells were stained with anti-FLAG tag antibody (green) as the primary antibody. The nuclei were stained with DAPI (Blue). Immunostained cells were visualized with a fluorescent microscope. The same magnification of $\times 200$ was used throughout.

\subsection{The Residues K358 and D360 Influence VP-Mediated ZIKV Inhibition}

We investigated whether the substitutions at positions 356, 358, and 360 may have had an influence on VP antiviral properties. To first determine whether expression of mutant $r$ Ps had an effect on cell viability at the time-point of ZIKV infection, caspase-3/7 activity was measured on cell lysates at $18 \mathrm{~h}$ post-transfection using a caspase $3 / 7$ kit assay (Figure S3). We observed that the expression of the rVP-D356A, rVP-K358R, and rVP-D360A resulted in a weak increase in caspase-3 activity compared to $\mathrm{rVP}{ }^{\mathrm{wt}}$. Thus, the three mutant rVPs were suitable for a comparative analysis of their antiviral activity against ZIKV.

To evaluate the antiviral effect of the mutant rVPs against ZIKV, A549 cells were transfected at $18 \mathrm{~h}$ with plasmids expressing either rVP-D356A, rVP-K358R, or rVP-D360A and then infected at $24 \mathrm{~h}$ with the ZIKV strain BR15 (Figure 5). Transfection with $\mathrm{pcDNA3/rVP}{ }^{\mathrm{wt}}$ served as a positive control. As expected, the expression of $r V P^{w t}$ prior to ZIKV infection reduced virus progeny production by at least 4 log. A comparable ZIKV inhibition was observed with rVP-D356A. In contrast, rVP-D360A was much less efficient at inhibiting ZIKV with a virus progeny production, which reduced by only 2 log. Unexpectedly, rVP-K358R showed no antiviral activity against ZIKV suggesting a critical role for residue Lys358 in VP-mediated ZIKV inhibition. Because rVP-K358R expression can greatly affect the metabolic activity of A549 cells, we tested whether rVP-K358R affects viability of ZIKV-infected cells. Using a caspase 3/7 kit assay, we only detected a weak increase in the rate of cell death in ZIKV-infected A549 cells expressing rVP-K358R compared to $\mathrm{rVP}^{\mathrm{wt}}$ (Figure S4). This suggested that the lack of anti-ZIKV activity was not related to increased apoptosis of A549 cells expressing rVP-K358R. Taken together, these results showed that both Lys358 and Asp360 influenced VP antiviral properties. We found that a single Lys-to-Arg substitution at position 358 resulted in a complete lack of VP antiviral activity against ZIKV.

We asked whether the lack of anti-ZIKV activity of rVP-K358R relates to its inability to inhibit viral replication. To investigate this issue, we used the recombinant GFP-expressing ZIKV (ZIKV GFP) derived from ZIKV historical African strain MR766 [14,25,26]. We previously demonstrated that GFP is a reliable reporter protein that monitors viral replication inside the infected host-cells $[14,25,26]$. A549 cells were transfected at $18 \mathrm{~h}$ with plasmids expressing $\mathrm{rVP}^{\mathrm{wt}}$ or mutant $\mathrm{rVPs}$ and then infected $24 \mathrm{~h}$ with $\mathrm{ZIKV}_{\mathrm{GFP}}$ at MOI (multiplicity of infection) of 2 (Figure 6). FACS analysis, showed that the expression of $\mathrm{rVP} \mathrm{wt}^{\mathrm{wt}}$ and its two mutant $\mathrm{rVP}-\mathrm{D} 356 \mathrm{~A}$ and $\mathrm{rVP}-\mathrm{D} 360 \mathrm{~A}$ reduced the rate of GFP-positive A549 cells by $90 \%$ compared to mock-transfected cells. In contrast, the expression of rVP-K358R showed no effect on ZIKV replication efficiency in A549 cells. Together, these results showed that a Lys-to-Arg substitution at position 358 abrogated VP ability to inhibit ZIKV replication regardless of viral strain origin. 


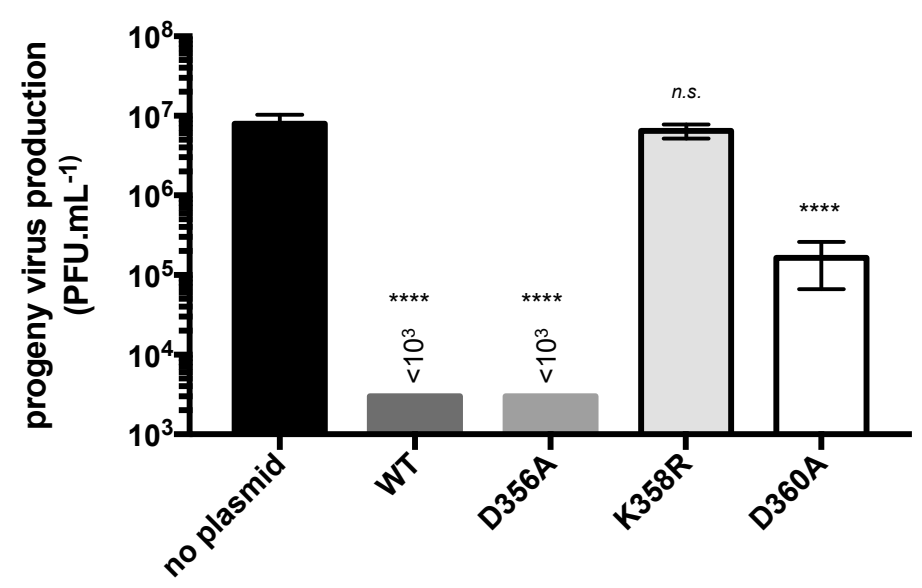

Figure 5. Antiviral activity of rVP mutants against ZIKV. A549 cells were transfected at $18 \mathrm{~h}$ with plasmids expressing rVPwt (WT), rVP-D356A (D356A), rVP-K358R (K358R), or rVP-D360A (D360A) or mock-transfected (no plasmid). Cells were infected at $24 \mathrm{~h}$ with ZIKV strain BR15 at MOI of 1. Virus progeny production was determined by a plaque forming assay on Vero cells. Results were expressed as the mean $( \pm \mathrm{SEM})$ of three independent assays. $p$-values were determined on the comparison with no plasmid. ${ }^{* * * *} p<0.0001$, n.s, not significant, $p<0.05$.
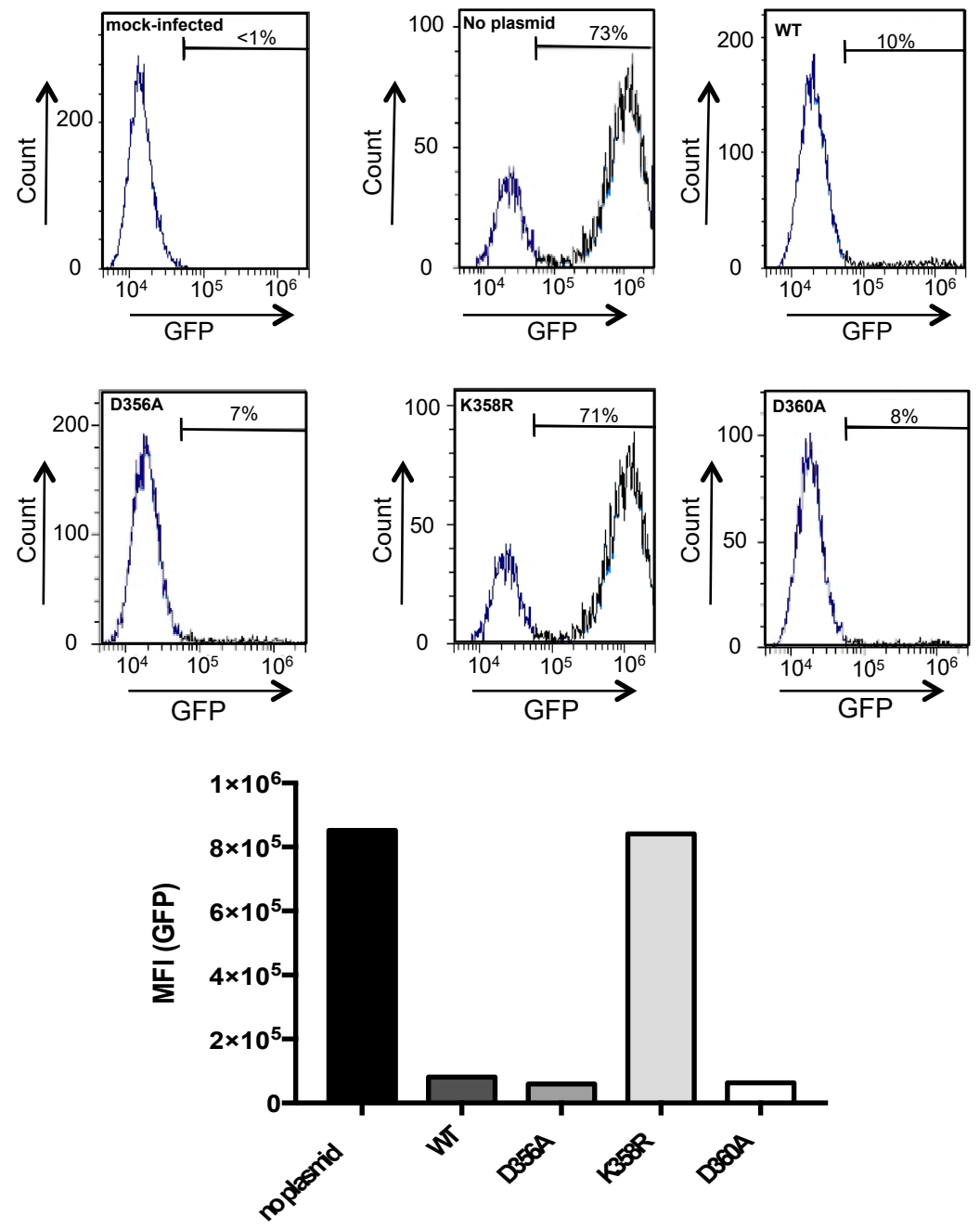

Figure 6. Antiviral action of mutant rVPs against ZIKV replication. A549 cells were transfected $18 \mathrm{~h}$ with plasmids expressing rVPwt, rVP-D356A, rVP-K358R, or rVP-D360A or mock-transfected (no plasmid). Cells were infected $24 \mathrm{~h}$ with $\mathrm{ZIKV}_{\mathrm{GFP}}$ at MOI of 2. The percentage of GFP-positive cells and the MFI were determined by FACS analysis. 


\subsection{Concluding Remarks}

Viperin has been evaluated as one of the ISG-encoded proteins playing a major role in the antiviral innate immune response against ZIKV [12-14]. The underlying molecular mechanisms of viperin antiviral action against ZIKV have been partially resolved. Viperin was found to bind to and cause degradation of viral NS3 protein by a proteasome-dependent proteolytic pathway [13]. It has also been found that viperin is able to produce a chain terminator for the RNA-dependent RNA polymerase NS5 [22]. Although a direct connection between these two antiviral mechanisms is not obvious, it is likely that viperin inhibits ZIKV by interrupting viral RNA synthesis inside the host-cell.

The purpose of our study was to investigate the role of the amino-acid residues 356 to 360 in viperin antiviral properties against ZIKV. The viperin antiviral properties were analyzed in human epithelial A549 cells, which were transient transfected with a plasmid vector overexpressing recombinant human viperin. We confirmed that the expression of our recombinant viperin greatly inhibited ZIKV growth in A549 cells. Immunoblot analysis detected a weak level of recombinant viperin protein in transiently transfected A549 cells. It has been reported that viperin could be subjected to proteolysis by the proteasome [11]. Mutational analysis revealed that the C-terminal amino-acid residues 356 to 360 may have had an influence on the viperin protein level. To our knowledge, this is the first report suggesting a role for the last C-terminal amino-acid residues in the biochemical properties of viperin. Given that substitutions D356A, K358R, and D360A increased the level of viperin expression in A549 cells, the charged amino-acid residues at positions 356, 358, and 360 might have played an important role in viperin stability. Understanding the mechanisms by which Asp356, Lys358, and Asp360 influence the stability of human viperin is a critical issue that will be the subject of further investigation.

An important observation was that a mutant viperin bearing the K358R substitution lacked anti-ZIKV activity whereas D360A substitution only resulted in a partial loss of its antiviral action. Our data identified Lys358 as a key amino acid for viperin antiviral action against ZIKV. Mechanisms by which the C-terminal amino acid residue Lys358 influences viperin antiviral properties remain to be understood. It has been reported that the ER membrane-associated viperin has ability to self-assemble leading to formation of oligomers [24]. Furthermore, it was extrapolated that protein oligomerization links to the C-terminal domain of viperin [24]. Future studies will investigate whether the lack of anti-ZIKV activity of a mutant viperin bearing the K358R substitution could be related to a defect of protein oligomerization. It is also of interest to determine whether viperin could be subjected to a post-translational modification though a protein-protein interaction-dependent mechanism. Interestingly, sequence analysis of the last C-terminal amino-acid residues of human viperin identified the tetrapeptide Leu357-Lys358-Leu359-Asp360 as a possible SUMO-interaction motif $\psi \mathrm{KxD}$ where $\psi$ represented a hydrophobic residue. SUMOylation is a post-translational modification of proteins in response to internal and external stimuli including viral infection [27-31]. SUMOylation results in the formation of an isopeptide bond between the C-terminal SUMO di-glycine motif and the $\xi$-amino group of a lysine residue within the SUMO motif of the target protein [32,33].

It is tempting to infer that the tetrapeptide Leu357-Lys358-Leu359-Asp360 at the C-terminal region of viperin was subjected to a post-translational modification by SUMOylation. The involvement of Asp360 in a putative SUMO-interaction motif LKLD is based on the fact that a mutant viperin bearing a D360A substitution was able to partially rescue ZIKV growth in A549 cells. The engagement of Lys358 into a mechanism of SUMOylation is supported by the finding that the Lys-to-Arg change which retained a positive charge at position 358 abrogated the ability of VP to inhibit ZIKV. We noted that the expression of mutant viperin bearing the K358R substitution resulted in a marked reduction in A549 cell metabolic activity whereas wild-type viperin showed no effect on cell metabolic activity. The metabolic activity reduction was associated with a particular profile in the cellular distribution of such a mutant viperin. Whether there is a potential link between the lack of anti-ZIKV activity of VP-K358R and its effect on cell metabolism is still an open issue. Further studies will determine whether Lys358 is a key amino acid in both biochemical and antiviral properties of viperin. 


\section{Materials and Methods}

\subsection{Cell Lines and Virus}

Vero cells (ATCC, CCL81) were cultured in Minimum Essential Media (MEM) supplemented with 5\% heat-inactivated fetal bovine serum (FBS). A549-Dual ${ }^{\mathrm{TM}}$ cells (Invivogen Inc, Toulouse, France) designated hereafter as A549 cells were grown in MEM medium supplemented with 10\% heat-inactivated FBS, non-essential amino acids, $10 \mu \mathrm{g} \mathrm{mL}^{-1}$ blasticidin and $100 \mathrm{mg} \mathrm{mL}^{-1} \mathrm{zeocin}^{-}$ (InvivoGen, Toulouse, France). The molecular clone BR15 derived from epidemic Brazilian ZIKV strain

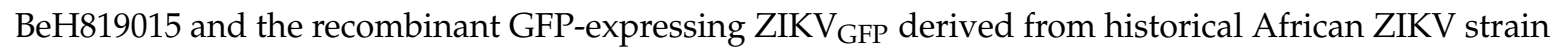
MR766-NIID have been described elsewhere [8,25]. Virus stocks were grown on Vero cells. Infectivity of ZIKV was determined by a plaque-forming assay on Vero cells [34]. Cells were routinely infected with ZIKV at the MOI of 1 or 2 plaque-forming units (PFU) per cell.

\subsection{Antibodies}

Mouse anti-viperin antibody clone MaP.VIP was purchased from Sigma-Aldrich (Saint-Quentin-Fallavier, France). The mouse anti-DDDDK tag mAb (anti-FLAGtag antibody), goat anti-mouse and goat anti-rabbit immunoglobulin-horseradish peroxidase (HRP) conjugated secondary antibodies were purchased from Abcam (Cambridge, UK). DAPI was purchased from Euromedex (Souffelweyersheim, France). The rabbit anti- $\alpha$ tubulin polyclonal Ab was purchased from Santa Cruz Biotechnology (Dallas, Texas, USA).

\subsection{Vector Plasmids Expressing Viperin and Its Mutants}

The coding sequences for human viperin (Genbank accession number AAL50053) or its mutants

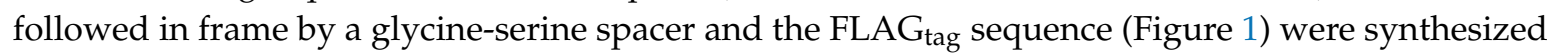
and cloned into Nhe I and Not I restriction sites of the pcDNA $3.1(+)$ Neo plasmid by Genecust (Luxembourg). The recombinant plasmids were verified by sequencing (Genecust, Luxembourg). Plasmids were transfected in A549 cells using Lipofectamin ${ }^{\mathrm{TM}} 3000$ according to the manufacturer's instructions (Thermo Fisher Scientific, Illkirch-Grafenstaden, France).

\subsection{Flow Cytometry Analysis}

A549 cells $\left(1.5 \times 10^{5}\right)$ were fixed with $3.7 \%$ paraformaldehyde $(\mathrm{PFA})$ in phosphate buffered saline (PBS) for $10 \mathrm{~min}$. For the detection of rVPs, cells were permeabilized with $0.15 \%$ of Triton X-100 in PBS and then incubated with anti-FLAGtag antibody (dilution 1:2000) for $1 \mathrm{~h}$ at room temperature. Goat anti-mouse Alexa Fluor 488 IgG antibody was used as a secondary antibody. For ZIKV $\mathrm{GFP}_{\mathrm{G}}$, infected cells were fixed and then observed for GFP expression. For each assay, $10^{4}$ cells were analyzed by flow cytometry (CytoFLEX, Beckman Coulter, Brea, California, USA) using FlowJo software (BD Bioscience, Le Pont-de-Claix, France).

\subsection{Immunofluorescence Assay}

A549 cells $\left(1.5 \times 10^{5}\right)$ were grown on coverslips and fixed with $3.7 \%$ PFA for 10 min and permeabilized with $0.15 \%$ Triton $X-100$ in PBS for $4 \mathrm{~min}$. Cells were stained using the mouse anti-FLAG tag antibody and followed by goat anti-mouse Alexa Fluor 488 IgG secondary antibody. The nucleus was stained with DAPI and the cells were visualized with a Nikon Eclipse E2000-U microscope (Nikon, Lisses, France). Images were captured and treated using a Hamamatsu ORCA-ER camera (Hamamatsu, Japan) and the imaging software NIS-Element AR (Nikon, Lisses, France).

\subsection{Immunoblot Analysis}

Cells were lysed in urea buffer and cell lysates were separated by SDS-PAGE, transferred to nitrocellulose membranes and probed with primary antibody. The membranes were washed and then 
probed with goat anti-mouse or anti-rabbit immunoglobulin-HRP conjugated second antibody. Blots were revealed with ECL detection reagents.

\subsection{MTT Assay}

A549 cells were cultured in a 96-well plates at a density of $2 \times 10^{4}$ cells per well. Cell monolayers were rinsed with PBS $1 \times$ and incubated with culture growth medium mixed with $5 \mathrm{mg} \cdot \mathrm{mL}^{-1}$ MTT (3-[4,5-dimethylthiazol-2-yl]-2,5-diphenyltetrazolium bromide) solution for $1 \mathrm{~h}$ at $37^{\circ} \mathrm{C}$. MTT medium was removed and the formazan crystals were solubilized with dimethyl sulfoxide (DMSO). Absorbance was measured at $570 \mathrm{~nm}$ with a background subtraction at $690 \mathrm{~nm}$.

\subsection{Caspase $3 / 7$ Activity}

A549 cells were cultured in a 96-well plates at a density of $2 \times 10^{4}$ per well. Caspase $3 / 7$ activity in raw cell lysates was measured using a Caspase Glo®3/7 assay kit (Promega, Charbonnières-les-bains, France) according to the manufacturer's protocol. Caspase activity was quantified by luminescence using a FLUOstar Omega Microplate Reader (BMG LABTECH, Champigny-sur-Marne, France).

\subsection{Statistical Analysis}

Values of independent experiments were analyzed by ANOVA or t-tests as appropriate. Values of $p<0.05$ were considered statistically significant. Asterisks indicate that the differences were statistically significant: ${ }^{* * *} p<0.0001,{ }^{* * *} p<0.001,{ }^{* *} p<0.01,{ }^{*} p<0.1$.

Supplementary Materials: Supplementary materials can be found at http://www.mdpi.com/1422-0067/20/7/ 1574/s1.

Author Contributions: B.V. and P.D. conceived and designed the experiments. B.V., and G.G. performed the experiments. P.D. contributed to reagents/materials/analysis tools; B.V., G.G., and P.D. wrote the paper.

Funding: This work was supported by a grant from POE FEDER 2014-20 of the Conseil Général de La Réunion (ZIKAlert program, No. SYNERGIE: RE00001902). B.V. received funding from the ZIKAlert program.

Acknowledgments: We gratefully acknowledge the assistance of Etienne Frumence, Pascale Krejbich-Trotot, Juliano Haddad, and Wildriss Viranaicken.

Conflicts of Interest: The authors declare no conflicts of interest.

\section{Abbreviations}

$\begin{array}{ll}\text { CTP } & \text { Cytidine triphosphate } \\ \text { ddhCTP } & 3^{\prime} \text {-deoxy-3', } 4^{\prime} \text { didehydro-CTP } \\ \text { DENV } & \text { Dengue virus } \\ \text { DMSO } & \text { Dimethyl sulfoxide } \\ \text { ER } & \text { Endoplasmic reticulum } \\ \text { FBS } & \text { Fetal bovine serum } \\ \text { HCV } & \text { Hepatitis C virus } \\ \text { HRP } & \text { Horseradish-peroxidase } \\ \text { IFNs } & \text { Type I interferons } \\ \text { ISG } & \text { Interferon-stimulated gene } \\ \text { IF } & \text { Immunofluorescence } \\ \text { IFN } & \text { Type I interferons } \\ \text { IU } & \text { International unit } \\ \text { JEV } & \text { Japanese encephalitis virus } \\ \text { kDa } & \text { Kilo Dalton } \\ \text { mAb } & \text { Monoclonal antibody } \\ \text { MEM } & \text { Minimum Essential Media } \\ \text { MFI } & \text { Mean fluorescence intensity } \\ \text { MOI } & \text { Multiplicity of infection } \\ \text { MTT } & 3^{\prime} \text {-[4,5-dimethylthiazol-2-yl]-2,5-diphenyltetrazolium bromide }\end{array}$




$\begin{array}{ll}\text { NS } & \text { Non-structural } \\ \text { PBS } & \text { Phosphate buffered saline } \\ \text { PFA } & \text { Paraformaldehyde } \\ \text { RSAD2 } & \text { Radical SAM domain-containing 2 } \\ \text { rVPwt } & \text { Recombinant human viperin } \\ \text { SAM } & \text { S-adenosyl methionine } \\ \text { SDS-PAGE } & \text { Sodium dodecyl sulfate poly-acrylamide gel electrophoresis } \\ \text { TBEV } & \text { Tick-borne encephalitis virus } \\ \text { VP } & \text { Viperin } \\ \text { WNV } & \text { West Nile virus } \\ \text { YFV } & \text { Yellow fever virus } \\ \text { ZIKV } & \text { Zika virus }\end{array}$

\section{References}

1. Sikka, V.; Chattu, V.K.; Popli, R.K.; Galwankar, S.C.; Kelkar, D.; Sawicki, S.G.; Stawicki, S.P.; Papadimos, T.J. The Emergence of Zika Virus as a Global Health Security Threat: A Review and a Consensus Statement of the INDUSEM Joint working Group (JWG). J. Glob. Infect. Dis. 2016, 8, 3-15. [PubMed]

2. Musso, D.; Gubler, D.J. Zika Virus. Clin. Microbiol. Rev. 2016, 29, 487-524. [CrossRef] [PubMed]

3. Plourde, A.R.; Bloch, E.M. A Literature Review of Zika Virus. Emerg. Infect. Dis. 2016, 22, 1185-1192. [CrossRef]

4. Weaver, S.C.; Costa, F.; Garcia-Blanco, M.A.; Ko, A.I.; Ribeiro, G.S.; Saade, G.; Shi, P.Y.; Vasilakis, N. Zika virus: History, emergence, biology, and prospects for control. Antiviral Res. 2016, 130, 69-80. [CrossRef] [PubMed]

5. Haddow, A.D.; Schuh, A.J.; Yasuda, C.Y.; Kasper, M.R.; Heang, V.; Huy, R.; Guzman, H.; Tesh, R.B.; Weaver, S.C. Genetic characterization of Zika virus strains: Geographic expansion of the Asian lineage. PLoS Negl. Trop. Dis. 2012, 6, e1477. [CrossRef] [PubMed]

6. Lindenbach, B.D.; Rice, C.M. Molecular biology of flaviviruses. Adv. Virus Res. 2003, 59, 23-61. [PubMed]

7. Hasan, S.S.; Sevvana, M.; Kuhn, R.J.; Rossmann, M.G. Structural biology of Zika virus and other flaviviruses. Nat. Struct. Mol. Biol. 2018, 25, 13-20. [CrossRef] [PubMed]

8. Bos, S.; Viranaicken, W.; Turpin, J.; El-Kalamouni, C.; Roche, M.; Krejbich-Trotot, P.; Desprès, P.; Gadea, G. The structural proteins of epidemic and historical strains of Zika virus differ in their ability to initiate viral infection in human host cells. Virology 2018, 516, 265-273. [CrossRef] [PubMed]

9. Seo, J.Y.; Yaneva, R.; Cresswell, P. Viperin: A multifunctional, interferon-inducible protein that regulates virus replication. Cell Host Microbe 2011, 10, 534-539. [CrossRef]

10. Helbig, K.J.; Beard, M.R. The role of viperin in the innate antiviral response. J. Mol. Biol. 2014, 426, 1210-1219. [CrossRef] [PubMed]

11. Chan, Y.L.; Chang, T.H.; Liao, C.L.; Lin, Y.L. The cellular antiviral protein viperin is attenuated by proteasome-mediated protein degradation in Japanese encephalitis virus-infected cells. J. Virol. 2008, 82, 10455-10464. [CrossRef] [PubMed]

12. Van der Hoek, K.H.; Eyre, N.S.; Shue, B.; Khantisitthiporn, O.; Glab-Ampi, K.; Carr, J.M.; Gartner, M.J.; Jolly, L.A.; Thomas, P.Q.; Adikusuma, F.; et al. Viperin is an important host restriction factor in control of Zika virus infection. Sci. Rep. 2017, 7, 4475. [CrossRef] [PubMed]

13. Panayiotou, C.; Lindqvist, R.; Kurhade, C.; Vonderstein, K.; Pasto, J.; Edlund, K.; Upadhyay, A.S.; Överby, A.K. Viperin Restricts Zika Virus and Tick-Borne Encephalitis Virus Replication by Targeting NS3 for Proteasomal Degradation. J. Virol. 2018, 92, e02054-17. [CrossRef] [PubMed]

14. Vanwalscappel, B.; Tada, T.; Landau, N.R. Toll-like receptor agonist R848 blocks Zika virus replication by inducing the antiviral protein viperin. Virology 2018, 522, 199-208. [CrossRef]

15. Lindqvist, R.; Overby, A.K. The Role of Viperin in Antiflavivirus Responses. DNA Cell Biol. 2018, 37, 725-730. [CrossRef] [PubMed]

16. Wang, X.; Hinson, E.R.; Cresswell, P. The interferon-inducible protein viperin inhibits influenza virus release by perturbing lipid rafts. Cell Host Microbe 2007, 2, 96-105. [CrossRef] [PubMed]

17. Wang, S.; Wu, X.; Pan, T.; Song, W.; Wang, Y.; Zhang, F.; Yuan, Z. Viperin inhibits hepatitis C virus replication by interfering with binding of NS5A to host protein hVAP-33. J. Gen. Virol. 2012, 93 Pt 1, 83-92. [CrossRef] 
18. Nasr, N.; Maddocks, S.; Turville, S.G.; Harman, A.N.; Woolger, N.; Helbig, K.J.; Wilkinson, J.; Bye, C.R.; Wright, T.K.; Rambukwelle, D.; et al. HIV-1 infection of human macrophages directly induces viperin which inhibits viral production. Blood 2012, 120, 778-788. [CrossRef]

19. Helbig, K.J.; Eyre, N.S.; Yip, E.; Narayana, S.; Li, K.; Fiches, G.; McCartney, E.M.; Jangra, R.K.; Lemon, S.M.; Beard, M.R. The antiviral protein viperin inhibits hepatitis $C$ virus replication via interaction with nonstructural protein 5A. Hepatology 2011, 54, 1506-1517. [CrossRef] [PubMed]

20. Helbig, K.J.; Carr, J.M.; Calvert, J.K.; Wati, S.; Clarke, J.N.; Eyre, N.S.; Narayana, S.K.; Fiches, G.N.; McCartney, E.M.; Beard, M.R. Viperin is induced following dengue virus type-2 (DENV-2) infection and has anti-viral actions requiring the C-terminal end of viperin. PLoS Negl. Trop. Dis. 2013, 7, e2178. [CrossRef] [PubMed]

21. Upadhyay, A.S.; Vonderstein, K.; Pichlmair, A.; Stehling, O.; Bennett, K.L.; Dobler, G.; Guo, J.T.; Superti-Furga, G.; Lill, R.; Överby, A.K.; et al. Viperin is an iron-sulfur protein that inhibits genome synthesis of tick-borne encephalitis virus via radical SAM domain activity. Cell. Microbiol. 2014, 16, 834-848. [CrossRef] [PubMed]

22. Gizzi, A.S.; Grove, T.L.; Arnold, J.J.; Jose, J.; Jangra, R.K.; Garforth, S.J.; Du, Q.; Cahill, S.M.; Dulyaninova, N.G.; Love, J.D.; et al. A naturally occurring antiviral ribonucleotide encoded by the human genome. Nature 2018, 558, 610-614. [CrossRef] [PubMed]

23. Jiang, D.; Guo, H.; Xu, C.; Chang, J.; Gu, B.; Wang, L.; Block, T.M.; Guo, J.T. Identification of three interferon-inducible cellular enzymes that inhibit the replication of hepatitis C virus. J. Virol. 2008, 82, 1665-1678. [CrossRef] [PubMed]

24. Hinson, E.R.; Cresswell, P. The N-terminal amphipathic alpha-helix of viperin mediates localization to the cytosolic face of the endoplasmic reticulum and inhibits protein secretion. J. Biol. Chem. 2009, 284, 4705-4712. [CrossRef] [PubMed]

25. Gadea, G.; Bos, S.; Krejbich-Trotot, P.; Clain, E.; Viranaicken, W.; El-Kalamouni, C.; Mavingui, P.; Desprès, P. A robust method for the rapid generation of recombinant Zika virus expressing the GFP reporter gene. Virology 2016, 497, 157-162. [CrossRef] [PubMed]

26. Gaudry, A.; Bos, S.; Viranaicken, W.; Roche, M.; Krejbich-Trotot, P.; Gadea, G.; Desprès, P.; El-Kalamouni, C. The Flavonoid Isoquercitrin Precludes Initiation of Zika Virus Infection in Human Cells. Int. J. Mol. Sci. 2018, 19, 1093. [CrossRef] [PubMed]

27. Wohlschlegel, J.A.; Johnson, E.S.; Reed, S.I.; Yates, J.R. Global analysis of protein sumoylation in Saccharomyces cerevisiae. J. Biol. Chem. 2004, 279, 45662-45668. [CrossRef] [PubMed]

28. Yang, X.J.; Chiang, C.M. Sumoylation in gene regulation, human disease, and therapeutic action. F1000Prime Rep. 2013, 5, 45. [CrossRef] [PubMed]

29. Sahin, U.; Ferhi, O.; Carnec, X.; Zamborlini, A.; Peres, L.; Jollivet, F.; Vitaliano-Prunier, A.; de Thé, H.; Lallemand-Breitenbach, V. Interferon controls SUMO availability via the Lin28 and let-7 axis to impede virus replication. Nat. Commun. 2014, 5, 4187. [CrossRef] [PubMed]

30. Doiron, K.; Goyon, V.; Coyaud, E.; Rajapakse, S.; Raught, B.; McBride, H.M. The dynamic interacting landscape of MAPL reveals essential functions for SUMOylation in innate immunity. Sci. Rep. 2017, 7, 107. [CrossRef]

31. Lowrey, A.J.; Cramblet, W.; Bentz, G.L. Viral manipulation of the cellular sumoylation machinery. Cell Commun. Signal. 2017, 15, 27. [CrossRef] [PubMed]

32. Hay, R.T. SUMO: A history of modification. Mol. Cell 2005, 18, 1-12. [CrossRef] [PubMed]

33. Geiss-Friedlander, R.; Melchior, F. Concepts in sumoylation: A decade on. Nat. Rev. Mol. Cell Biol. 2007, 8, 947-956. [CrossRef] [PubMed]

34. Frumence, E.; Roche, M.; Krejbich-Trotot, P.; El-Kalamouni, C.; Nativel, B.; Rondeau, P.; Missé, D.; Gadea, G.; Viranaicken, W.; Desprès, P. The South Pacific epidemic strain of Zika virus replicates efficiently in human epithelial A549 cells leading to IFN-beta production and apoptosis induction. Virology 2016, 493, 217-226. [CrossRef] [PubMed]

(C) 2019 by the authors. Licensee MDPI, Basel, Switzerland. This article is an open access article distributed under the terms and conditions of the Creative Commons Attribution (CC BY) license (http://creativecommons.org/licenses/by/4.0/). 